\title{
Identification and synthesis of impurities formed during sertindole preparation
}

\author{
I. V. Sunil Kumar ${ }^{* 1}$, G. S. R. Anjaneyulu ${ }^{1}$ and V. Hima Bindu ${ }^{2}$
}

\section{Full Research Paper}

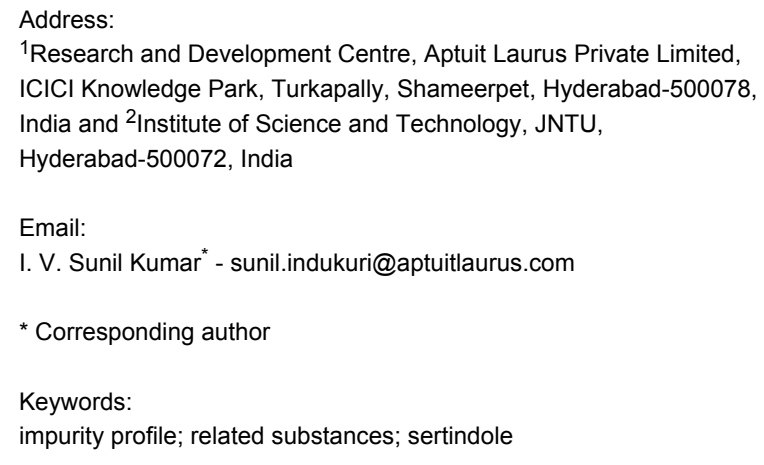

${ }^{1}$ Research and Development Centre, Aptuit Laurus Private Limited, ICICI Knowledge Park, Turkapally, Shameerpet, Hyderabad-500078, India and ${ }^{2}$ Institute of Science and Technology, JNTU, Hyderabad-500072, India

Email:

I. V. Sunil Kumar ${ }^{*}$ - sunil.indukuri@aptuitlaurus.com

* Corresponding author

Keywords:

impurity profile; related substances; sertindole

Beilstein J. Org. Chem. 2011, 7, 29-33.

doi:10.3762/bjoc. 7.5

Received: 29 September 2010

Accepted: 23 November 2010

Published: 07 January 2011

Associate Editor: N. Sewald

(c) 2011 Sunil Kumar et al; licensee Beilstein-Institut. License and terms: see end of document.

\begin{abstract}
Sertindole (1), an atypical anti-psychotic drug is used for the treatment of schizophrenia. During the laboratory optimization and later during its bulk synthesis the formation of various impurities was observed. The impurities formed were monitored and their structures were tentatively assigned on the basis of their fragmentation patterns in LC-MS. Most of the impurities were synthesized and their assigned constitutions confirmed by co-injection in HPLC. We describe herein the formation, synthesis and characterization of these impurities. Our study will be of immense help to others to obtain chemically pure sertindole.
\end{abstract}

\section{Introduction}

The safety of a drug product is not only dependent on the toxicological properties of the active drug substance (or API), but also on the impurities formed during the various chemical transformations. Therefore, identification, quantification, and control of impurities in the drug substance and drug product are important parts of drug development for obtaining marketing approval. It is more challenging for an organic chemist to identify the impurities which are formed in very small quantities in a drug substance. Since most of the time it is very difficult to identify and control impurities within acceptable levels in the process, extra purification steps may then be necessary thereby making the process less competitive. More often than not, the syntheses of impurities are not described in the literature which makes it even more difficult for the organic chemist who must then design a synthesis, which is time consuming. The development of a drug substance is incomplete without the identification of an impurity profile involved in the process. Furthermore, it is not mandatory to design synthetic routes for the impurities. Thus, in our study we explored the formation, identification, synthesis and characterization of impurities found in the preparation of sertindole. This study will be of immense help for organic chemists to understand the potential impurities in sertindole synthesis and thereby obtain the pure compound.

Sertindole (1) (Figure 1), displays broad pharmacological profile and mainly affects dopamine $\mathrm{D}_{2}$, serotonin $5-\mathrm{HT}_{2}$ and $\alpha_{1}$-adrenergic receptors [1-5]. It is a potent centrally acting $5-\mathrm{HT}_{2}$ receptor antagonist in vivo and finds application in the 


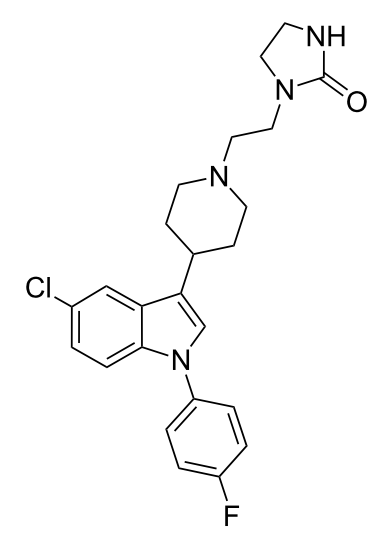

1 sertindole

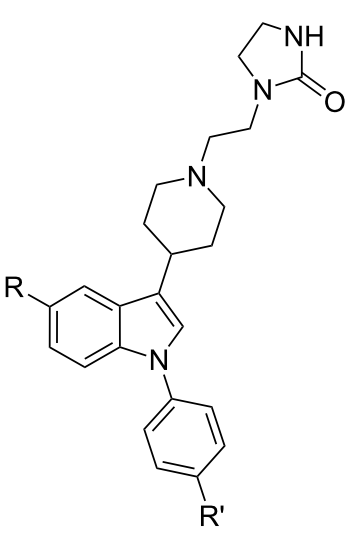

$2 \mathrm{R}=\mathrm{H}, \mathrm{R}^{\prime}=\mathrm{F}$ $3 \mathrm{R}=\mathrm{Cl}, \mathrm{R}^{\prime}=\mathrm{H}$

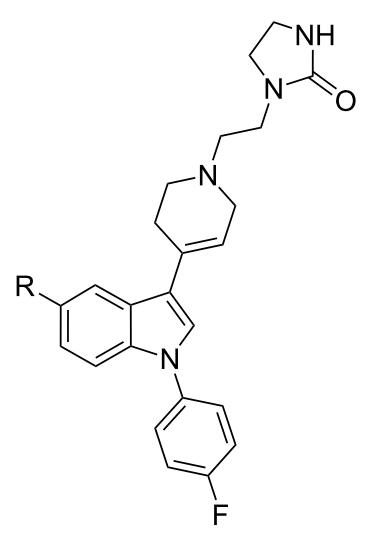

$4 \mathrm{R}=\mathrm{H}$

$5 \mathrm{R}=\mathrm{Cl}$

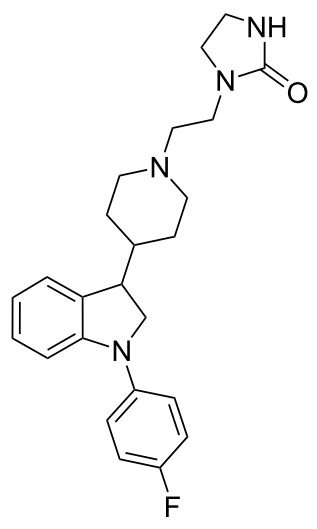

6<smiles>[R]CCN1CCC(c2cn(-c3ccc(F)cc3)c3ccc(Cl)cc23)CC1</smiles><smiles>[R]=C[Y]n1cc[nH]c1=O</smiles>

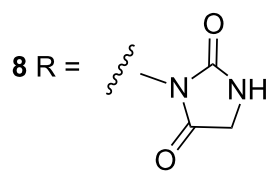<smiles>Fc1ccc(-n2cc(C3CCNCC3)c3cc(Cl)ccc32)cc1</smiles>

9<smiles>O=C1NCCN1CCN1CCC(c2c[nH]c3ccc(Cl)cc23)CC1</smiles>

10

Figure 1: Sertindole (1), process related impurities and metabolites.

treatment of anxiety, hypertension, drug abuse and cognitive disorders. It has been reported to show antipsychotic effect in clinical studies. In contrast to other antipsychotics, sertindole has no associated sedative effects; sedation may add to the cognitive problems inherent in schizophrenia.

Sertindole is designated chemically as 1-[2-[4-[5-chloro-1-(4fluorophenyl)- $1 H$-indol-3-yl]-1-piperidinyl]ethyl]-2-imidazolidinone. Its literature synthesis (Scheme 1) [1-5] involves the copper catalyzed $\mathrm{N}$-arylation of 5-chloroindole (11) with 4-fluorobromobenzene (12). The product, 5-chloro-1-(4fluorophenyl)indole (13), on treatment with 4-piperidinone hydrochloride monohydrate (14) under acidic conditions affords 5-chloro-1-(4-fluorophenyl)-3-(1,2,3,6-tetrahydropyridin-4-yl)$1 \mathrm{H}$-indole hydrochloride (15). Reduction of $\mathbf{1 5}$ in the presence of platinum oxide yields 5-chloro-1-(4-fluorophenyl)-3-(4piperdinyl)- $1 H$-indole (9) which on condensation with 1-(2chloroethyl)imidazolidinone (16) in the presence of a base gives sertindole (1).

During the laboratory optimization of sertindole (1), many process related impurities were identified. The guidelines recommended by ICH state that the acceptable levels for a known and unknown compound (impurity) in the drug should be less than 0.15 and $0.10 \%$, respectively [6]. In order to meet the stringent regulatory requirements, the impurities present in the drug substance must be identified and characterized. Literature reports [5,7-9] include impurities formed due to either over reduction (e.g., 2, 3 and 6) [5,7], incomplete reduction (e.g., 4 and 5) $[5,8]$ or due to incomplete alkylation (e.g., 9 and 10) $[5,7]$. However, no synthetic details have been reported. In this context, the present study describes identification, synthesis and characterization of impurities formed during sertindole synthesis.

\section{Results and Discussion}

During the catalytic hydrogenation of indole 15, formation of $0.5-1.0 \%$ of the des-chloro indole $\mathbf{1 7}$ is observed; the level is reduced to less than $0.1 \%$ during its isolation and purification. It is necessary to remove the impurity at this stage because after condensation with imidazolidinone 16, it is difficult to remove the des-chloro sertindole $\mathbf{2}$, from sertindole, without significant loss in yield. The impurity $\mathbf{2}$ was prepared by palladium catalyzed hydrogenation of indole $\mathbf{9}$ and the des-chloro indole 17 formed was condensed with imidazolidinone 16, under Finkelstein conditions (Scheme 2). 


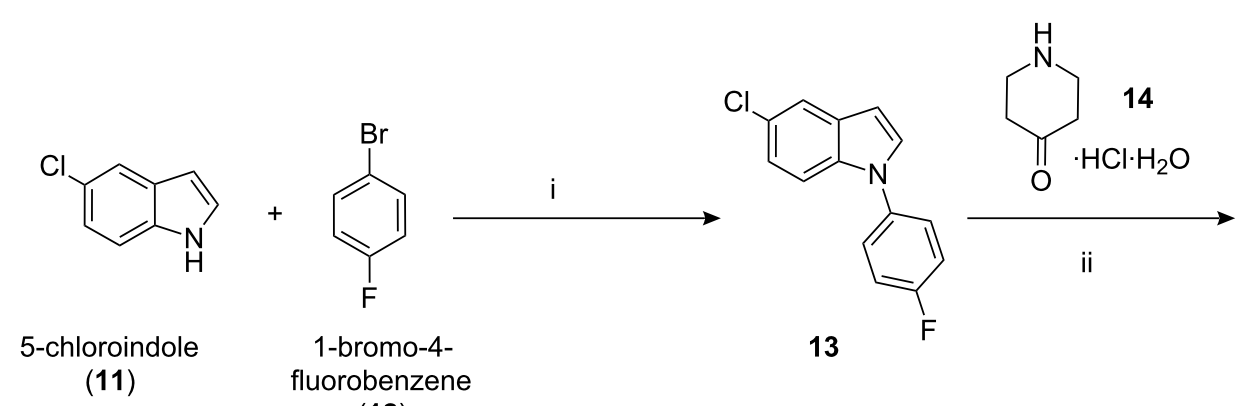

(12)

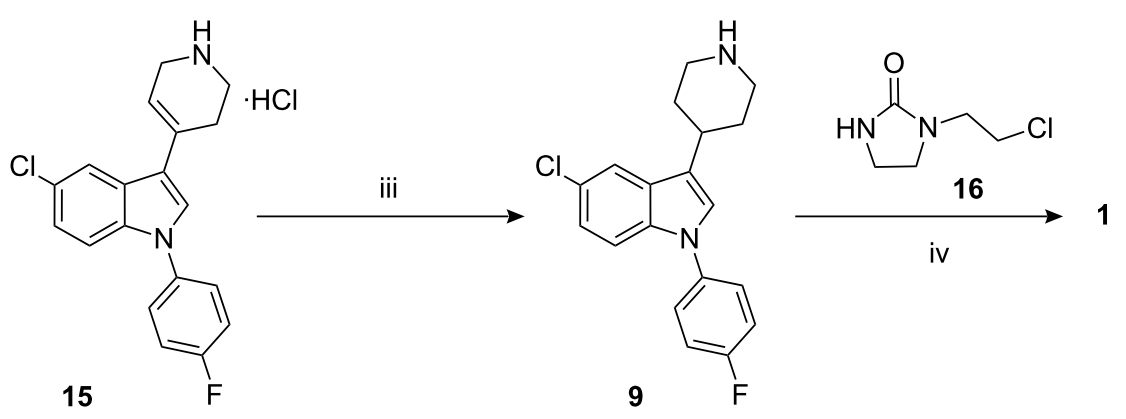

Scheme 1: Reagents and conditions: i) $\mathrm{K}_{2} \mathrm{CO}_{3}$, $\mathrm{CuBr}$, ethylenediamine, $\mathrm{DMF} 130-135{ }^{\circ} \mathrm{C}$; ii) $\mathrm{CH}_{3} \mathrm{COOH}, \mathrm{CF}_{3} \mathrm{COOH}, 100-110{ }^{\circ} \mathrm{C}$; iii) $\mathrm{PtO}_{2} / \mathrm{H}_{2}$, methanol, $30-35^{\circ} \mathrm{C}$; iv) $\mathrm{K}_{2} \mathrm{CO}_{3}, \mathrm{KI}$, methylisobutyl ketone (MIBK), $110-115^{\circ} \mathrm{C}$.

The platinum catalyzed reduction of indole $\mathbf{1 5}$ is a critical reaction, whilst a prolonged reaction time leads to dehalogenated product $\mathbf{2}$, termination without complete reduction leads to indole 9 contaminated with $\mathbf{1 5}$. This contaminated material upon condensation with imidazolidinone $\mathbf{1 6}$ results in sertindole (1) contaminated with $\mathbf{5}$. The degree of contamination was $0.02-0.10 \%$ [10]. It is difficult to remove the impurity 5 from sertindole (1). Indole 5 was prepared by condensation of $\mathbf{1 5}$ with 1-(2-chloroethyl)imidazolidinone (16) in the presence of base (Scheme 3).

During the $\mathrm{N}$-arylation of 5-chloroindole (11) with 1-bromo-4fluorobenzene (12), formation of traces of 5-chloro-1-(4-

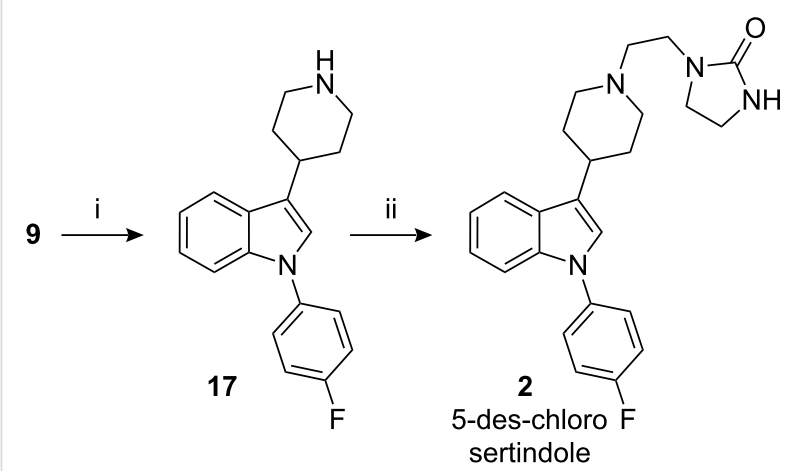

Scheme 2: Reagents, conditions (and yields): i) (a) pH adjusted to 6; (b) $\mathrm{Pd} / \mathrm{C}, \mathrm{HCOONH}{ }_{4}, \mathrm{AcOH}, \mathrm{MeOH}$, reflux (77.6\%); ii) $16, \mathrm{~K}_{2} \mathrm{CO}_{3}, \mathrm{KI}$, MIBK, reflux $(44.5 \%)$. bromophenyl) indole (18) along with the desired indole 13 was observed. A detail study of this coupling reaction revealed significant formation of this undesired indole in the absence of a transition metal, especially when cesium carbonate was used for the coupling reaction. Sertindole (1) synthesized from this contaminated material was found to contain impurity $\mathbf{2 1}$ at levels of $0.05-0.25 \%$ [10]. In order to quantify and limit the impurities in the final drug substance, indole $\mathbf{1 8}$ was converted to the corresponding $N$-(4-bromophenyl)-impurity 21 (Scheme 4). The catalytic hydrogenation of indole 19 proved to be a difficult reaction as significant formation of the dehalogenated products was observed, repeated recrystallization from $\mathrm{MeOH}$ afforded pure indole 20.

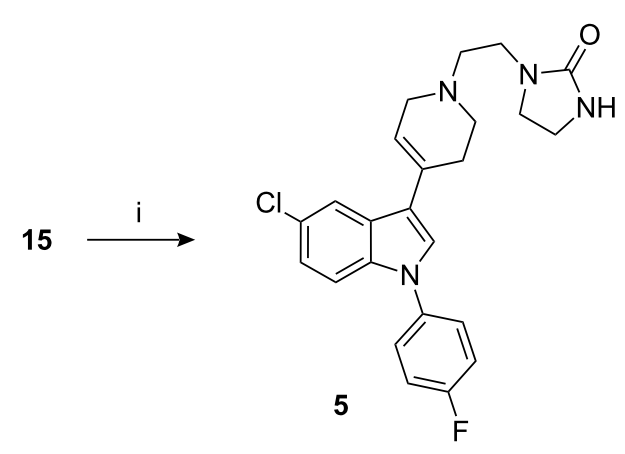

Scheme 3: Reagents, conditions (and yields): i) 16, $\mathrm{K}_{2} \mathrm{CO}_{3}, \mathrm{KI}, \mathrm{MIBK}$, reflux $(73.9 \%)$. 


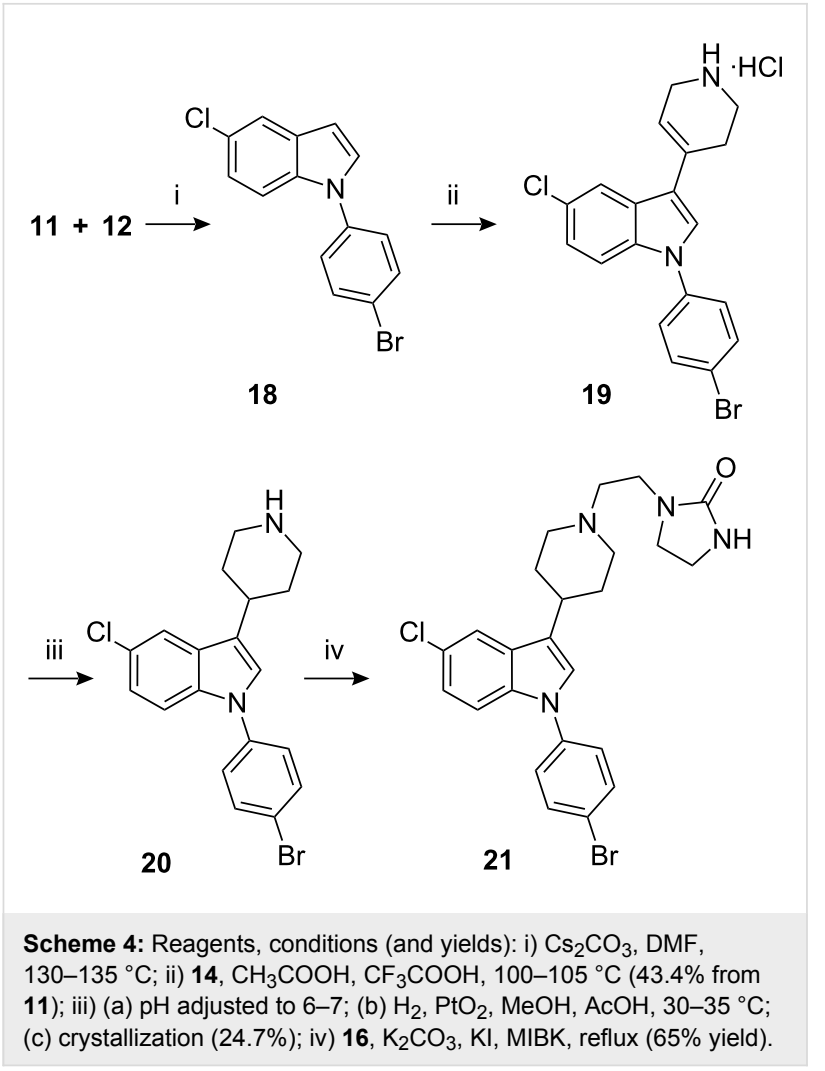

Since dehalogenation was observed during the platinum oxide reduction of the tetrahydropyridinyl moiety in indole $\mathbf{1 9}$, this reaction was utilized to synthesize the des-fluoro sertindole $\mathbf{3}$. Thus prolonged hydrogenation of $\mathbf{1 9}$ afforded des-fluoro indole 22, which on condensation with imidazolidinone $\mathbf{1 6}$ afforded the desired compound $\mathbf{3}$ (Scheme 5). The contamination by $\mathbf{3}$ in sertindole (1) was $0.20-0.50 \%$ [10].

In some of commercial samples, 5-chloroindole was found to be contaminated with traces of 5-bromoindole (23), although the amount of contamination of the bromo analogue 27 in sertindole (1) was never more than $0.02 \%$. The bromo analogue of

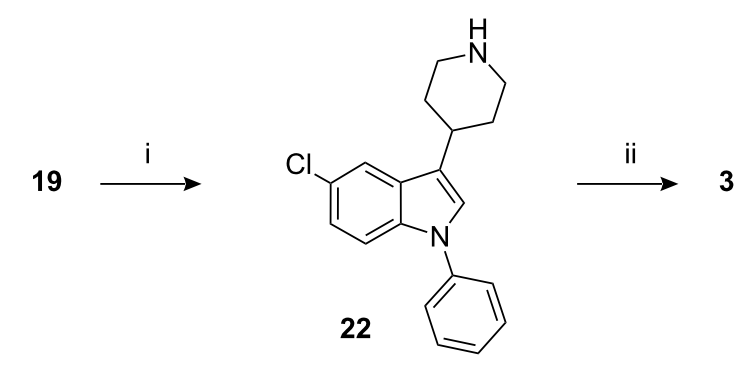

Scheme 5: Reagents, conditions (and yields): i) (a) pH adjusted to 6-7; (b) $\mathrm{H}_{2}, \mathrm{PtO}_{2}, \mathrm{MeOH}, \mathrm{AcOH}, 30-35^{\circ} \mathrm{C}$ (73\% yield); ii) $16, \mathrm{~K}_{2} \mathrm{CO}_{3}$, $\mathrm{KI}, \mathrm{MIBK}$, reflux (52\%).

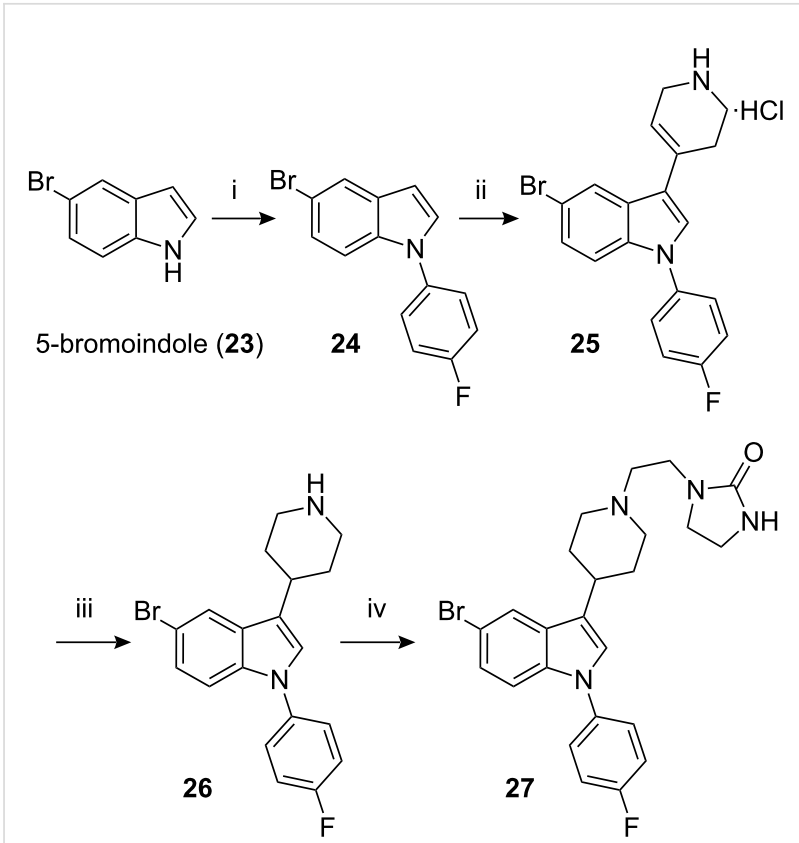

Scheme 6: Reagents, conditions (and yields): i) $12, \mathrm{~K}_{2} \mathrm{CO}_{3}, \mathrm{Cu}(\mathrm{II}) \mathrm{Br}$, ethylenediamine, DMF, $130-135^{\circ} \mathrm{C},(51 \%)$; ii) $14, \mathrm{CH}_{3} \mathrm{COOH}$, $\mathrm{CF}_{3} \mathrm{COOH}, 100-105^{\circ} \mathrm{C}$ (57\%); iii) (a) pH adjusted to 6-7; (b) $\mathrm{PtO}_{2} / \mathrm{H}_{2}$ $\mathrm{MeOH}, 30-35^{\circ} \mathrm{C}$; (c) column chromatography (33.3\%); iv) $16, \mathrm{~K}_{2} \mathrm{CO}_{3}$, $\mathrm{KI}, \mathrm{MIBK}$, reflux (64.3\%).

sertindole (27) was synthesized from 5-bromoindole (23) following the reaction sequence used to synthesize $\mathbf{1}$ (Scheme 6).

During the $N$-alkylation reaction there is always the probability of dialkylation, hence the dialkylated piperidine $\mathbf{2 8}$ was synthesized by prolonged condensation of imidazolidinone 16 with sertindole (1), followed by purification by column chromatography (Scheme 7). The contamination by $\mathbf{2 8}$ in sertindole (1) was $0.25-0.45 \%[10]$.<smiles>O=C1NCCN1CC[N+]1(CCN2CCNC2=O)CCC(c2cn(-c3ccc(F)cc3)c3ccc(Cl)cc23)CC1</smiles>

Scheme 7: Reagents, conditions (and yield): i) (a) 16, $\mathrm{Et}_{3} \mathrm{~N}, \mathrm{Nal}$, $\mathrm{CH}_{3} \mathrm{CN}$, reflux; (b) column chromatography (19.1\%). 
Sertindole $N$-oxide 29, a possible contaminant that can be formed by air oxidation, was prepared by oxidation of sertindole (1) with $m$-chloroperbenzoic acid (Scheme 8 ). The contamination by $\mathbf{2 9}$ in sertindole (1) was $<0.05 \%$ [10].

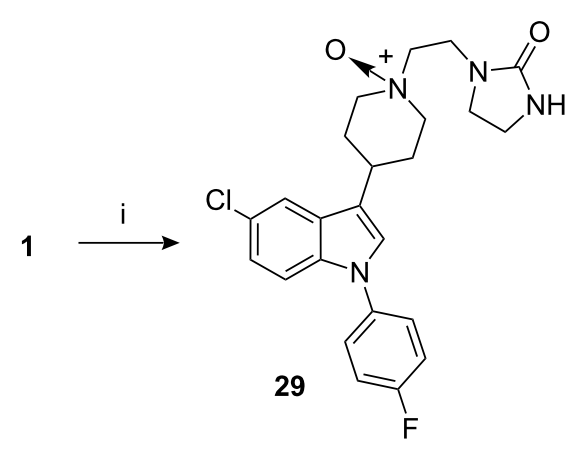

Scheme 8: Reagents, conditions (and yield): i) (a) $\mathrm{mCPBA}, \mathrm{MeOH}$, $40-45^{\circ} \mathrm{C}$; (b) column chromatography $(52.2 \%)$.

\section{Conclusion}

For the better understanding of the synthetic pathway of an active pharmaceutical ingredient (API) it is necessary to identify all the impurities formed/anticipated. In this regard we have synthesized and characterized different potential process-related impurities of sertindole.

\section{Supporting Information}

Experimental procedure (Supporting Information File 1); HPLC chromatograms, ${ }^{1} \mathrm{H}$ and ${ }^{13} \mathrm{C}$ NMR spectra of compounds 2, 3, 5, 9, 21, 27, 28 and 29 (Supporting Information File 2). HPLC chromatogram containing sertindole (1) spiked with process related impurities and LC-MS fragmentation data [10] is included in Supporting Information File 2.

\section{Supporting Information File 1}

Full experimental details and characterization data for all new compounds.

[http://www.beilstein-journals.org/bjoc/content/ supplementary/1860-5397-7-5-S1.pdf]

\section{Supporting Information File 2}

${ }^{1} \mathrm{H}$ and ${ }^{13} \mathrm{C}$ NMR spectral data and HPLC chromatograms for all new compounds.

[http://www.beilstein-journals.org/bjoc/content/ supplementary/1860-5397-7-5-S2.pdf]

\section{Acknowledgements}

The authors wish to thank AptuitLaurus Private Limited for supporting this work.

\section{References}

1. Perregaard, J. K. Heterocyclic compounds. EP0200322, Nov 5, 1986.

2. Perregaard, J. K. 1-(4'-fluorophenyl)-3,5-substituted indoles useful in the treatment of psychic disorders and pharmaceutical compositions thereof. U.S. Patent 4710500, Dec 1, 1987.

3. Perregaard, J. K.; Skarsfeldt, T. Use of sertindole for the treatment of schizophrenia. EP0392959, Oct 17, 1990.

4. Zanon, J.; Villa, M.; Ciardella, F. Method for manufacture of sertindole. WO03/080597, Oct 2, 2003.

U.S. Patent Application 2009264656, Oct 22, 2009.

5. Perregaard, J.; Arnt, J.; Bøgesø, K. P.; Hyttel, J.; Sanchez, C. J. Med. Chem. 1992, 35, 1092-1101. doi:10.1021/jm00084a014

6. ICH guidelines, Q3A (R): Impurities in new drug products: The quality guidelines for active pharmaceutical ingredients related to impurities according to the International Conference of Harmonization. 2002; http://www.ich.org.

7. Pearlstein, R. A.; Vaz, R. J.; Kang, J.; Chen, X. L.; Preobrazhenskaya, M.; Shchekotikhin, A. E.; Korolev, A. M.; Lysenkova, L. N.; Miroshnikova, O. V.; Hendrix, J.; Rampe, D. Bioorg. Med. Chem. Lett. 2003, 13, 1829-1835. doi:10.1016/S0960-894X(03)00196-3

8. Andersen, K.; Liljefors, T.; Gundertofte, K.; Perregaard, J.; Bøgesø, K. P. J. Med. Chem. 1994, 37, 950-962. doi:10.1021/jm00033a013

9. Tzeng, T.-B.; Stamm, G.; Chu, S.-y. J. Chromatography B 1994, 661, 299-306. doi:10.1016/0378-4347(94)00356-4

10. The degree of formation of the impurities and the HPLC chromatogram included in the Supporting Information File S2, page 29, is for samples of sertindole (1) obtained before laboratory optimization.

\section{License and Terms}

This is an Open Access article under the terms of the Creative Commons Attribution License (http://creativecommons.org/licenses/by/2.0), which permits unrestricted use, distribution, and reproduction in any medium, provided the original work is properly cited.

The license is subject to the Beilstein Journal of Organic Chemistry terms and conditions:

(http://www.beilstein-journals.org/bjoc)

The definitive version of this article is the electronic one which can be found at: doi:10.3762/bjoc. 7.5 